\title{
Roma 1956: Ramón Gaya, puente entre Tomás Segovia y María Zambrano
}

\section{Rome 1956: Ramón Gaya, a Bridge between Tomás Segovia and María Zambrano}

\author{
Ricardo TEJADA MíngueZ \\ Université du Maine \\ ricardo.tejada@yahoo.es
}

Recibido: 23 de noviembre de 2010

Aceptado: 24 de noviembre de 2010

\section{Resumen}

El artículo trata del encuentro que tuvo lugar en abril de 1956, en Roma, entre María Zambrano, Ramón Gaya y Tomás Segovia. Después de trazar previamente los puntos de convergencia entre los tres autores, antes de dicha fecha, se detiene en evocar y desarrollar dos recuerdos de los dos últimos protagonistas, así como en analizar su visión de la «ciudad eterna». Por fin, sostiene que el sentido profundo de este encuentro fue el de hacernos descubrir un nuevo sentido poético de lo real. Los tres lo exploraron desde ángulos distintos y permanecerán fieles a esta llamada de lo real. Los tres nos enseñan que lo real sólo puede ser escuchado en un esfuerzo generoso, pasivo y heroico, hacia lo otro, por debajo de las ideologías, del consumismo y de las pululantes pantallas de todo tipo que nos lo velan, erigiendo realidades mostrencas y lenitivas.

Palabras clave: R. Gaya, T. Segovia, Z. Zambrano, estética, exilio, belleza.

\begin{abstract}
The present article touches on the meeting occurred in Rome, in April 1956, between María Zambrano, Ramón Gaya y Tomás Segovia. After sketching converging points between the three authors prior to the meeting, this paper evokes and develops the memories of the two latter, and analyses their visions of the "eternal city".
\end{abstract}


Ultimately, it states that deep reason of that meeting was to make us discover a new poetic sense of the real. The three authors show us that the real can be solely be listened through a generous, passive and heroic effort toward the otherness and hence underneath ideologies, consumerism and all range of pullulating screens that prevent us from the real by erecting monstrous and lenitive realities.

Keywords: R. Gaya, T. Segovia, Z. Zambrano, aesthetics, exile, beauty.

Hablar al mismo tiempo de tres figuras tan importantes como Gaya, Zambrano y Segovia no es nada fácil ${ }^{1}$. Hablar de un encuentro entre ellos lo es aún menos. Es como tocar tres pianos de manera simultánea. Cuando uno lee los ensayos de Ramón, de María y de Tomás, sobre todo los de los años 50, incluso cuando uno ve los cuadros del primero, los textos más filosóficos de la segunda o los poemas del tercero, tiene la extraña sensación de que se está leyendo una misma partitura, no igual, con modulaciones distintas, como si una sinfonía hubiese estado compuesta por tres compositores distintos, cuya singularidad irreductible fuese distinguible dentro de la masa instrumental, en el propio fluir musical.

Lo que quisiera hablarles es de un encuentro que tuvo lugar hace cincuenta y cuatro años. Un encuentro puede parecer a algunos, hoy en día, algo anecdóctico. Y es que hemos perdido casi totalmente el sentido de un encuentro, de algo que cambia, que transforma, que endereza la trayectoria de una persona o la reafirma, le hace saber que uno no está tan solo en sus propias ideas... Un encuentro puede ser incluso un acontecer que vaya más allá de la vida de las propias vidas personales.

En 1956, Ramón Gaya presenta María Zambrano a Tomás Segovia. Este es el sencillo guión que me he impuesto, sencillo y muy complicado porque no quisiera caer en explicaciones simplistas que hablen de tal o tal influencia, ni tampoco dejar de escuchar a cada uno de nuestros tres protagonistas en su irreductible voz individual. Son tres y uno más uno más una, de la misma forma que una pareja es dos y uno más uno, las dos cosas al unísono.

Si Gaya presentó Zambrano a Segovia es porque los dos primeros se conocían de antes. Es natural. A comienzos del 56, el pintor murciano tenía 45 años y la filósofa andaluza 51 años. El poeta valenciano iba a cumplir en mayo de aquel año los 29 años. La diferencia de edad entre éste y aquellos es notoria, pero no infranqueable. Gaya y Zambrano llevaban 17 años en el exilio. No habían tenido tiempo suficiente antes de la Guerra Civil como para madurar una obra suficientemente conocida por el gran público, pero lo poco que habían escrito y pintado les había bastado

\footnotetext{
${ }^{1}$ Agradezco de todo corazón a Tomás Segovia y a Isabel Verdejo por los recuerdos, precisiones y observaciones que me han transmitido en septiembre y octubre de 2010, mientras escribía esta ponencia, y por la paciencia que han tenido al responder a mis interrogantes.
} 
para anudar lazos de amistad muy sólidos con círculos intelectuales y artísticos de la España republicana.

Ramón y María se conocen probablemente en 1928 cuando el primero pasa por Madrid antes de ir a París. Más tarde, Gaya se instala regularmente en Madrid en enero de 1932. La relación cordial se vuelve después una relación de amistad a raíz de alguna de las Misiones Pedagógicas que Manuel Bartolomé Cossío, presidente del Patronato, organizó a partir de finales de 1931. Gaya estuvo más implicado en ellas que Zambrano pues formó parte del plantel que puso en marcha el museo ambulante de pintura desde octubre del 32 , y en especial, en la misión más larga de todas, la de Galicia, entre agosto y diciembre del 332. Nigel Dennis comenta en uno de sus artículos sobre este tema que ella se apuntaba "según la necesidad o la oportunidad" a ayudar a los organizadores del Museo Ambulante 3 . En una de las visitas del museo por Almería, Gaya conoció a su primera mujer, Fe Sanz, amiga de María Zambrano4. Ella conocía ya a $\mathrm{Fe}$ por lo menos desde 19305. Seguramente, Zambrano le habló a Fe del paso del Museo por Almería y le animó a que se acercarse a conocer a esos chicos tan dinámicos. A partir de 1935, aparece él de vez en cuando en las tertulias de los domingos a la tarde, en casa de los padres de Zambrano, en la Plaza Conde de Barajas. El mismo Dieste habló años más tarde de un grupo o de una generación de las Misiones Pedagógicas y creo que hay un acierto indudable en esta denominación pues este colectivo humano, después de pasar por Hoja Literaria formará el nucleo duro de la revista Hora de España, ya durante la Guerra Civil. De hecho, la ponencia colectiva, firmada por Gaya, Dieste, Sánchez Barbudo y Zambrano fue leída en nombre de todos los miembros del grupo por A.Serrano Plaja en el Congreso de escritores Antifascistas, celebrado en Valencia en 1937. Este puñado de amigos llegará a mantenerse en lo esencial, ya en el exilio mexicano, en el consejo de redacción de la revista Taller.

\footnotetext{
2 Del 27 de marzo al 1 de abril de 1932, ella participó por primera vez en una misión en Navas del Madroño (Cáceres). Luego vendrán las misiones de Beteta (Cuenca), Zalduendo (Alava), Vícar (Almería) y Villaluenga del Rosario (Cádiz). En el 34, el museo estuvo en varios pueblos de Almería (en Albox, Garrucha, Níjar y en Vélez-Málaga, precisamente, tierra natal de María). Para todos estos datos me apoyo en el excelente católogo Las Misiones Pedagógicas. 1931-1936, Sociedad Estatal de Conmemoraciones/Residencia de Estudiantes, Madrid, 2006, en especial la cronología realizada por E.Otero y M.García Alonso, pp.38-51, el listado de misiones, pp.507-517, y las páginas 45, 272, 345 y 495.

3 En op.cit., p.334. El artículo de N.Dennis se titula «El Museo del Pueblo» y es de obligada consulta para este tema, pp.329-345.

4 Ver Ramón Gaya de viva voz. Entrevistas (1977-1998), editorial Pre-Textos, Valencia, 2007.

${ }^{5}$ Carta del 29 de octubre, seguramente del 74, de María Zambrano a Agustín Andreu. En Cartas de La Pièce (Correspondencia con Agustín Andreu), Pre-Textos/Universidad Politécnica de Valencia, 2002, p.116.
} 
Creo que tanto Gaya como Zambrano, compartieron durante la Guerra una misma fe en la victoria del pueblo republicano y un mismo propósito, a caballo entre lo humanístico y lo místico, de renovar el arte, de purificarlo y dignificarlo, sin caer en la propaganda o en la demagogia ${ }^{6}$. Comparten también desde finales de los años 30 una desconfianza hacia las vanguardias artísticas, en particular su faceta deshumanizadora, y hacia el realismo a la manera soviética.

En esa hora de España que era la del alba, según lo había afirmado con plena esperanza el editorial del primer número, en 1937, España volvía a "tener historia", según Zambrano. "Hoy -dice ella- el español muere para vivir, para recuperar la historia que le falsificaron convirtiéndola en alucinante laberinto. Muere por romper el laberinto de espejos, la galería de fantasmas en que habían querido encerrarle, y recuperarse a sí mismo, a su razón de ser» 7 . Esa historia en la que confiaban les deja de repente aparcados de manera brutal en la cuneta. Desde entonces, tanto Zambrano como Gaya albergarán la creencia de que la vida, la creación, está más allá de la historia o, más bien, más acá. Gaya casi desde siempre; Zambrano, mucho más lentamente irá llegando a esta convicción pues tendrá que irse desprendiendo progresivamente del historicismo orteguiano.

Los tres pasan por México, a raíz de la derrota republicana del 39. Gaya se queda ahí hasta el 56, aunque desde el 52 realiza estancias en Francia e Italia. Zambrano apenas está un año en México pues ya desde el 40, y hasta el 53, su vida se moverá entre San Juan de Puerto Rico, París y, sobre todo, La Habana. Ninguno de los dos, pese a que el primero estuvo más tiempo, tuvo una gran afinidad con México. Seguramente, entre otros factores, les pesó no estar rodeados de suficientes pinturas, en el caso de él, y de libros de filosofía, en el caso de ella, como hubieran deseado. No tenemos constancia de un intercambio epistolar entre ambos en los años en los que está ella en el Caribe y él en México. No parece que tuvieran entonces mucha relación aunque seguramente estaban al corriente de lo que iban haciendo, gracias a los conocidos y amigos comunes. Las numerosas tarjetas postales que Gaya empieza a enviar a Zambrano a partir del 56, delata una indudable intensificación de la relación, algo que nos invita a pensar que dicha fecha, como veremos, más que un reencuentro es un verdadero encuentro ${ }^{8}$.

\footnotetext{
${ }^{6}$ El pueblo es «ese yacimiento que busca la cultura para vivificar sus raíces», dice Rosa Chacel en el $\mathrm{n}^{\circ} 1$ de enero del 37, p.18, el mismo número en el que Gaya comienza su polémica con Josep Renau sobre la naturaleza y función del cartelismo.

${ }^{7} \mathrm{~N}^{\circ} 4$, abril de 1937, p. 267.

8 En estas postales, Ramón Gaya habla de ella como de una «fratella» o de María y de Araceli, como «fratellas», como en la del 26 de mayo de 1958. Por otro lado, la dedicatoria de Ramón Gaya en el libro Velázquez. Pájaro solitario, editorial RM, que se encuentra en la biblioteca personal de Zambrano dice así: "A la fratella máxima, María Zambrano, de Ramón. Roma 6 de octubre de 1969". Obsérvese que la palabra "fratella" es una feminización, hecha intencionadamente por Gaya, de "fratello" ("hermano" en italiano) y que no existe en dicha lengua pues "hermana" se dice "sorella".
} 
En lo que se refiere a Tomás Segovia, llega él a México en el 40 después de vivir en París y en el protectorado francés de Marruecos. Lleva consigo dos rémoras a la hora de poder abrirse un camino en las letras: haber sido muy niño en los años 30 como para poder escribir algo y tener la ocasión de ser conocido en el mundillo de las letras, y sobre todo, vivir en un ambiente familiar más bien científico y no humanístico o de letras, dado que su padre adoptivo era médico y sus hermanas estudiantes de biológicas 9 . Pero cuenta con un viento a favor: la comunidad del exilio español, que en su sociabilidad tan comunitaria, favorece la emulación con respecto a los maestros y las ocasiones de ser reconocido por sus pares ${ }^{10}$. Seguramente, gracias a la relaciones de sus familiares y amigos, consigue entablar relación con Emilio Prados y Ramón Gaya, dos figuras fundamentales en su educación sentimental e intelectual. A Prados lo conoce primero, en 194311. Va a su casa y le lee sus primeros poemas. La relación de Segovia con Gaya tuvo un cariz más fraterno, más amistoso, que con Prados. Con éste se imponía el trato de usted, debido quizá, en parte, a la mayor diferencia de edad, de casi treinta años. Con Prados primaba más la devoción, no por ello menos afectuosa, que la admiración, más proclive ésta a la emulación.

Tenemos constancia de la amistad entre Gaya y Segovia desde 1947. La relación no será siempre fácil debido al orgullo, declarado del segundo, y a la tendencia a los desplantes o a las recriminaciones más o menos paternales del primero. Sin embargo, la afinidad en cuanto a las orientaciones fundamentales respecto a la creación se profundiza y se enriquece con el paso del tiempo. De estas fechas iniciales, en concreto de 1949, data el retrato que Ramón hace de Tomás. Su primer poemario es presentado por Gaya en México ese mismo año. En la presentación, cual buen maestro, señala los senderos positivos que debe seguir transitando y anota los elementos inmaduros que pueden ser corregidos en un futuro. Tuvo -dice él- "tanta precipicitación, tanta fatalidad de expresar unos sentimientos, unos sentimientos que él sabía tan propios, tan suyos, que no temió decirlos con palabras deliberadamente ajenas". Pero añade que no se trata de una imitación, sino del «desamparo» de un joven poeta que disgustado con la retórica de la poesía que se hacía en aquel tiempo, se dejaba inclinar hacia un poeta como Juan Ramón Jiménez, "tan clásico y venidero". Los poemas de Tomás, en una palabra, no tenían «voz», pero sí un «sentir propio»12. En una de las «Anotaciones de diario inéditas», recientemente

\footnotetext{
${ }^{9}$ Ver entrevista realizada por Daniel González Dueñas e Alejandro Toledo titulada «Tomás Segovia: los ojos abiertos a la noche», en AGULHA. Revista de Cultura $n^{\circ}$ especial, Fortaleza/ São Paulo, agosto de 2000. Consultable en: http://www.secrel.com.br/jpoesia/agsegovia.htm.

10 Cuenta T.Segovia en esta entrevista la sorpresa que le ocasionó encontrarse con un Ateneo Español repleto de gente cuando leyó en público, por primera vez, sus primerizos poemas. Era el año de 1947.

11 Sobre exiliados, El Colegio de México, México, 2007, p.221.

12 Ramón Gaya, Obra Completa, Editorial Pre-Textos/ Sociedad Estatal de Conmemoraciones Culturales, Valencia/Madrid, 2010, pp.281-283.
} 
dadas a la luz, Gaya anota lo siguiente, con fecha 13 de abril de 1953: "Carta de Tomás y su conferencia. Me gusta la conferencia, y aunque haya muchas cosas mías, las fija de una manera muy personal y habiéndolas pensado de nuevo"13. Aquí ya no es tanto la inclinación hacia Juan Ramón Jiménez, poeta que hará de verdadero yunque de su amistad, como la percatación de que esta atracción significa por parte del más joven la adopción de ciertos hábitos mentales ajenos, pero repensándolos desde bases nuevas.

Este papel de Gaya como conductor severo pero púdicamente afectuoso, al mismo tiempo, se transparenta en las anotaciones de Gaya de 1955. Escribe Segovia: entre las personas a las que juzga él "soy la única que aprecia". Pero lo que le incomoda de su actitud es que al resto "las acepta o las rechaza (Cernuda, por ejemplo) pero no se le ocurre orientarlas". Claro, añadiríamos, porque a Cernuda (ya consagrado mientras que Segovia era por aquel entonces un perfecto desconocido) no quiere corregirlo o mejorarle actitudes u orientaciones. Lo da por imposible. Tomás, en esta época, se siente juzgado y ve que no tiene razones que justifiquen su posición. Era joven y es normal que Gaya quisiese enderezarle probablemente por las expectativas que él mismo generaba. Los juicios que hace Gaya de él piensa que se basan en su imagen, pero no en él mismo. La queja era justa, pero, como se dice, por sus obras los conoceréis... Lo que le incomodaba entonces era la sospecha de que había algo "paternal" en su actitud. Y a raíz de un disgusto que le ocasionó Gaya al gritarle, al parecer, a su mujer de aquel entonces, Inés Arredondo, anota Segovia a propósito de él: "la única persona que me separaba todavía de la soledad absoluta" 14 .

Cuando afloran algunos roces entre ambos es cuando precisamente está leyendo Segovia con gran asombro y admiración El hombre y lo divino de Zambrano. El es, así pues, uno de los pocos exiliados y, españoles en general, de los que sepamos, que leen y comprenden el libro poco después de salir en las librerías, un texto, como saben ustedes, de deslumbrante belleza y poderío conceptual, muy difícil de asimilar de un primer trago. "Magníficas páginas de María Zambrano sobre el pitagorismo", dice él. Enseguida se da cuenta de la importancia del capítulo «La condenación aristotélica de los pitagóricos», uno de los ensayos escritos poco antes de 1955, después de haberle entregado a Camus y a Caillois una primera versión en 1951 en la que no aparece este texto, del que por cierto es otro español exiliado instalado en los Estados Unidos, José Ferrater Mora, quien se apercibe rápidamente de su importancia en carta enviada a Zambrano por esas fechas ${ }^{15}$. Y líneas más tarde sigue

\footnotetext{
13 Op.cit., p.561.

14 Tomás Segovia, El tiempo en los brazos. Cuaderno de notas (1950-1983), Valencia, Editorial PreTextos, 2009, pp.176, 212-214.

15 Me refiero a la carta fechada el 19 de septiembre de 1955, consultable en la Fundación Zambrano, de Vélez-Málaga. Incluso el poeta Luis Cernuda se da cuenta de la importancia del libro pues en carta
} 
comentando Segovia su deslumbramiento ante dicho libro: "páginas magníficas" sobre "la luz, sobre lo sagrado, sobre la destrucción de los dioses". Y termina anotando: "tengo que escribir un pequeño artículo sobre el libro de María Zambrano. Me gusta muchísimo ese libro y quisiera hacer algo bonito". Líneas más tarde, en el mismo diario, alaba sobre todo en ella una voz "muy madura, sabia, tierna" ya que se constata un "respeto de lo real" 16 . En cambio, lo poco que Gaya escribió sobre la obra de su amiga es más contenido. Lo que le inquietaba -como anotó en una ocasión- era su gusto por los símbolos, algo que podía emborronar precisamente lo real17. En este sentido, hay un juego muy sutil en los tres autores, de dosificación de lo simbólico, mayor o menor, en la aprehensión de lo real, en el que Segovia se sitúa de alguna manera en un término medio, entre el poder revelador del símbolo, muy zambraniano, y la aprehensión intuitiva, visionaria, de alguna manera, de lo real al modo gayesco.

En la primavera del 55, Segovia le va leyendo a Gaya los capítulos que va escribiendo de La flauta de Marsias, ensayo que dejará inédito como tal y del que publicará algunos extractos con los que ahora no se identifica mucho. Según Tomás, su trato, por aquel entonces, (antes del verano del mismo año en el que se produce ese incidente con su mujer), es mucho más agradable pues está enfrascado en la pintura, se le ve productivo. "De cualquier forma -añade- es imprescindible que se vaya a Europa (también yo)"18. Es probablemente la lectura del libro de Zambrano lo que estará en el origen de unas conversaciones con Gaya sobre ella y lo que avivará en el joven poeta el deseo de ir a Roma a visitarla.

De vuelta de su primer viaje a Europa, el 18 de junio de 1953, Gaya había escrito: "algunos buenos amigos han venido a recibirme. Un cielo espléndido, de una belleza desmesurada. Todo parece asentado en su lugar. No, no falta nada, o casi nada. Falto... yo. Veremos cuándo llego". La pregunta que uno se hacía al leer esto era: ¿estaba ahí Tomás Segovia? Las «Anotaciones de diario inéditas» lo confirman. Estaba él19. Ramón Gaya volverá dos años y medio más tarde a aquella luz mediterránea, aquella luz no desmesurada (que se le había quedado tan entrañada desde su infancia en Murcia), a recuperar su yo perdido, pero esta vez acompañado de Tomás Segovia, su prometedor y orgulloso «discípulo», cada vez más cerca de ser una especie de «hermano menor». Según testimonio reciente de Tomás, Gaya le

\footnotetext{
a María Zambrano, del 15 de mayo del 55, dice haber oído que le van a publicar a ella un libro en FCE, la "Fonda de Incultura Expensiva", (como dice él con ironía, un tanto injusta), lo cual es "un tour de force porque no editan sino traducciones".

16 Op.cit., pp.213, 215 y 222 y, en especial, pp.233-235, en donde pondera todos los elogios que dirige al libro de Zambrano.

17 "Las personas dadas al simbolismo (como María) cambian la realidad por sus símbolos en vez de ver por transparencia los símbolos que hay en la realidad, que forman parte de ella, pero que no la sustituyen.” En Obra Completa, op.cit., p.468.

18 Op.cit., p.184.

19 Op.cit., pp. 450 y 568.
} 
habló a Zambrano de él y ésta le escribió al joven poeta para que le enviase unos poemas con el fin de que fuesen publicados en la revista internacional Botteghe Oscure. En efecto, en el cuaderno XVI de esta revista romana, tan exquisita -que publicaba textos narrativos, ensayos y poemas en cuatro idiomas- publicado en 1955, aparecerá un poema de él, «En brazos de la noche», el mismo número en el que aparece un capítulo de Delirio y destino, la autobiografía de Zambrano, titulado «La multiplicidad de los tiempos» 20 .

El año 55 es un año "muy decisivo" para Zambrano, como dice ella a Agustín Andreu en carta fechada el 23 de julio de 1975 pues escribe buena parte de lo que constituirá su libro futuro Los sueños y el tiempo ${ }^{21}$. Es un año especialmente duro para ella pues dos de los hombres que más había admirado y querido, José Ortega y Gasset y Gustavo Pittaluga, se enfermaron gravemente ${ }^{22}$. El que fuera su maestro moriría pocos meses más tarde. Los artículos de la filósofa sobre su figura y su obra son numerosos en este periodo 23 . La razón poética se encaminará desde entonces por unos linderos, los del sueño, los de la aurora, bastante desprendidos de la dualidad orteguiana «yo y su circunstancia». No hay ajuste de cuentas a nivel filosófico, pero la frecuencia con la que habla de su antiguo maestro delata unos distanciamientos conceptuales que se harán notorios desde los años 60. En cuanto a Pittaluga, amigo íntimo en su periodo cubano, se recobrará momentaneamente de esta enfermedad, aunque por poco tiempo 24 .

\footnotetext{
20 Se encuentran en la biblioteca personal de María Zambrano, custodiada por la Fundación del mismo nombre, en Vélez-Málaga, tres libros de T.Segovia: Siete poemas [publicado en marzo de 1955, Los presentes, México, y anticipo de Luz de aqui], Partición, (Pretextos, Valencia, 1983) y Primavera muda (Los Presentes, México, noviembre de 1954). El primero y el tercero están dedicados. La dedicatoria del primero es la siguiente: "A María Zambrano, ahora en el centro del mundo como siempre en el del espíritu, con la admiración de Tomás Segovia. México, julio de 55". La dedicatoria del tercero, no fechada, es la siguiente: "A María, este pequeño libro, que es una de las cosas que hago además de "bellos sonetos" (y de verás es sólo un pequeño "además") con la fe de Tomás Segovia". Es probable que Segovia le regalase a Zambrano, en Roma o poco tiempo antes, por correo, estos libros dedicados, justo anteriores a su estancia en Italia en 1956.

${ }^{21}$ Cartas de La Pièce, op.cit., p.248. Y en carta del 10 de agosto de 1975 dice estar ella "de parto" y habla de "un pensamiento y su despliegue hace ya largo tiempo concebido -Roma 1955", p.275.

22 A eso hay que añadir por estas fechas la enojosa noticia de que su marido, del que estaba separada, quisiese comenzar los trámites del divorcio en México. Carta de Alfonso Rodríguez Aldabe a María Zambrano del 6 de mayo de 1953.

${ }^{23}$ Mencionemos, por ejemplo: «Don José»: Ínsula, Madrid, año X, n. ${ }^{\circ} 119$, noviembre de 1955; «La filosofía de Ortega y Gasset»: Ciclón, La Habana, vol. 2, n. ${ }^{\circ}$ 1, enero de 1956; «Ortega y Gasset, filósofo y maestro»: El Nacional, Caracas, 12 de enero de 1956; «José Ortega y Gasset»: Cuadernos del Congreso por la libertad de la cultura, París, enero-febrero de 1956; y «Unidad y sistema en la filosofía de Ortega y Gasset»: Sur, Buenos Aires, n. ${ }^{\circ}$ 241, julio-agosto de 1956 (número homenaje a Ortega y Gasset). Todos estos artículos figuran, además de otros textos de diversa índole, en la edición, que acaba de salir, de Escritos sobre Ortega, de María Zambrano, Trotta, 2011, a cargo del que esto suscribe.

24 Tres cartas de amigos comunes le llegan a María desde Cuba, en el mes de mayo de 1956, expresando su pésame por la muerte de Gustavo Pittaluga. Su muerte fue, al parecer, el 27 de abril del 56,
} 
Como se ve, el viaje a Europa se programa con bastante antelación. Gaya tiene seguramente la intención desde la primavera del 55 de instalarse definitivamente en Italia. Al principio tiene la tentación de vivir en Venecia, la ciudad que más le deslumbra y embelesa, pero al final se decide por Roma. ¿Jugó un papel María Zambrano en esta decisión? ¿Le convenció para que se quedase en la capital italiana? No lo sabemos. Lo que sí sabemos es que buena parte de las amistades que tenía ella en Roma, como Ellemire Zola, Elena Croce, Diego de Mesa, Jorge Guillén, entre otros, pasarán a formar parte de su propia red de relaciones.

1956 es un año marcado por los incidentes universitarios de Madrid del mes de febrero que fueron el pretexto para que el régimen franquista declarase el estado de sitio y terminase con ese espejismo de liberalización cultural que supuso el ministerio de Ruiz-Giménez y el rectorado de Laín Entralgo. Desde fuera, las cosas se vieron con un prudente escepticismo. Los exiliados saben, por lo menos desde el ingreso de España en la UNESCO en 1952, ratificado al año siguiente, que las cosas van para largo. Una conciencia fuerte del exilio se apodera de muchos corazones. La sensación de que pueden morir fuera de la patria se hace cada vez más verosímil, con todo el dolor que eso entraña. A finales del 56, el estallido del conflicto de Suez, que coleaba desde principios del año, deja a las claras el carácter irreversible del impulso anticolonialista y el declive del Imperio Británico. Por estas fechas, en noviembre, se produce también la tentativa de democratizar el socialismo húngaro, aplastado sin miramientos por el Ejército soviético. Pocos intelectuales, en especial de izquierdas, denuncian la ocupación militar, de entre los cuales destaca Albert Camus. Es ya una primera señal de alarma de la verdadera naturaleza de un régimen supuestamente desestalinizado. Pero el mismo Camus advertía a los que se habían unido a él en esta protesta: no se puede denunciar lo de Budapest si no se denuncia la opresión franquista. La realpolitik del periodo de la guerra fría mostraba así toda su crudeza y cinismo 25 .

1957 será el año precisamente de la concesión del Premio Nobel a Camus. Tomás Segovia es un gran admirador de su obra, en especial en aquella época, lo que se verá plasmado en varios ensayos ${ }^{26}$. María Zambrano había tratado de publicar El Hombre y lo divino en Gallimard desde 1950 y se había puesto en contacto con el autor de La peste. De hecho, en estancias anteriores, en París, lo había trata-

no sabemos si poco después de que estuviesen en Roma, visitándola, Tomás y Ramón, o durante su estancia, pues desconocemos los días exactos que se quedaron en Roma.

25 Para estas informaciones históricas me he basado en los libros de Eric Hobsbawn, Historia del siglo XX, Crítica, 1995; Tony Judt, Postguerra. Una historia de Europa desde 1945, Círculo de Lectores, 2006; y José Luis Abellán, Ortega y Gasset y los orígenes de la transición, Espasa, 2000.

26 «Camus y la literatura comprometida», 1956, «Nuevas obras de Camus», «Camus y la universalidad», 1957, publicados los tres en Revista de la Universidad de México; «El exilio o el reino de Camus», 1957, y «Camus ida y vuelta», 1959, publicados en Revista Mexicana de Literatura; y «Acercamientos a la tragedia», 1958, recopilado en Contra-corrientes, UNAM, México, 1973. 
do. Seguramente cuando se conocieron Segovia y Zambrano en Roma hablaron de él. Los dos exiliados se sintieron bastante cercanos a la crítica camusiana del absolutismo de la historia, de la divinización del progreso y de las ideas abstractas, sin olvidar su gran afinidad con su búsqueda de la felicidad, bañada por el sol y la luz del Mediterraneo, su devoción por Grecia y su apego a la encarnación viva de sus mitos $^{27}$. El Camus de Segovia es un Camus claramente nietzscheano, de afirmación de la vida. Es "poesía viva". Gaya no comparte con ellos este respeto y valoración por su obra, quizá atribuible a su «galofobia»y, en general, a su desconfianza por todo lo que huela a «moralismo»e «intelectualismo» 28 .

El año anterior, en 1956, obtuvo el Premio Nobel Juan Ramón Jiménez. Tomás Segovia escribe unos cuantos artículos por esta época en los que elogia su clasicismo y su ambición metafísica, a contracorriente de los que ya no lo leían desde 1939 o por ignorancia o por prejuicios alimentados por su trato personal ${ }^{29}$. La poesía de Juan Ramón tiene la virtud, según él, de hurtarse a la elección entre una poesía abstracta, pura, deshumanizada, que los poetas vanguardistas o postvanguardistas preconizaban todavía, y una poesía propagandística, social, en la que el poema sirva de pretexto para canalizar reivindicaciones políticas. Lo más urgente, dice Tomás, es que la poesía sea el "testimonio de la hermosura del mundo" y la obra de Juan Ramón, en especial, la del exilio, muestra a las mil maravillas que se puede hacer una poesía que sea un homenaje al mundo y a la vida y, al mismo tiempo, una poesía que piensa. En esto último, Segovia va a encontrar amarres conceptuales en Filosofía y poesía de María Zambrano que le confirmen en esta vía. En cuanto a Gaya, la admiración por Juan Ramón, un poeta del que no se alejó nunca, como dijo en un ocasión, es aún más incondicional. En carta de Ramón a Juan Guerrero, fechada el 22 de febrero de 1953, en Venecia, le dice que le "impresionaron las prosas de J.R.J., magníficas, hechas (...) desde un lugar que sólo han alcanzado unos pocos, los más altos, un lugar que está después de la realidad, pero en el que la realidad, claro, no ha sido escamoteada sino traspasada"30. Y en la misma carta le habla de Tomás Segovia, uno de los pocos jóvenes que no siguen a Antonio Machado y

\footnotetext{
27 Jesús Moreno Sanz apunta con razón que, pese a este respeto, a María Zambrano le parecía un tanto de amateur la «filosofía» de Camus, aunque, añado, no era la única persona en reprochárselo, un tanto injustamente, por ejemplo, Sartre. Véase su artículo «Tres cartas de Camus a María Zambrano, breve historia de una amistad y una publicación malogradas», en María Zambrano. 1904-1991. De la razón cívica a la razón poética, Residencia de Estudiantes/Fundación Zambrano, 2004, pp.307-321.

28 En carta de R.Gaya a T.Segovia, fechada el 19 de febrero de 1958, en Roma, dice alegrarse de su "comunicación con Camus, aunque yo... ya no comparto tu admiración por él (...) Su vanidad (...) me fa veramente schifo [me da asco]". En R.Gaya, Algunas cartas, Pre-Textos, 1997, p.57.

29 «Actualidad de Juan Ramón», Cuadernos Americanos, 1954; «Juan Ramón Jiménez», Revista de la Universidad de México, 1957; y «Juan Ramón o el artista», La Cultura en México (suplemento de Siempre), 1957.

30 R.Gaya, Obra Completa, tomo IV, ed., introd. y notas de N. Dennis, 2000, p.167.
} 
que, por el contrario, "admira mucho" a Juan Ramón y "sabe muy bien quién es“31. Su palabra poética, había afirmado en 1942, es como si, haciéndo gancho, "hurgara, removiera los pozos más secretos de la verdad" 32 . Es indudable que el peculiar ensayismo gayesco es incomprensible sin el hálito juanramoniano.

En las semanas anteriores al viaje, Segovia está nervioso. Ignoramos el estado de ánimo de Gaya que va con él en el avión. No le hace ninguna gracia presentarse en "la oficina del gobierno franquista". El pasaje lo reserva para el 21 de marzo del 56. Tiene la cabeza ocupada en el viaje. "Imposible escribir, pensar, casi leer". Piensa que hasta su vuelta de Europa no podrá escribir poesía. No será así. "La conmoción de este viaje tiene que despertarme definitivamente"33. La anotación del 6 de marzo, pocos días antes del viaje, expresa su voluntad de "recobrar un poco de virginidad"34.

Sabemos por una carta de María Zambrano a Rosa Chacel, fechada el 1 de abril que los estaba esperando en Roma para dentro de quince días ${ }^{35}$. Ni en los «Retales de un diario» ni en las «Anotaciones de diario inéditas» de Gaya contamos con observaciones del mes de abril. En los «Cuadernos de notas» de Segovia saltamos del 6 de marzo al 11 de mayo, cuando ya está de regreso en México. De la importancia de este reencuentro con Europa para Segovia dan muestra las cartas que al parecer escribió "todos los días" de su viaje a su mujer de entonces, Inés Arredondo. De Zambrano no hemos encontrado por el momento referencias concretas acerca de este encuentro.

Tenemos, por el contrario, una serie de estampas de ciudades que escribió Tomás Segovia durante ese viaje, publicadas con el título de «Notas de viaje» en la Revista de la Universidad de México ${ }^{36}$. Hablan, por este orden, de París, de Chartres, de Venecia, de Florencia, de Roma, y como colofón unas «Divagaciones mediterráneas». Si las cotejamos con las estampas de ciudades del Cuaderno de viaje de Gaya, publicadas en el 54, podemos constatar que de todas ellas había hablado Ramón antes, aunque otras, como por ejemplo Asís, Pisa o Siena, no figuren en las notas de Segovia ${ }^{37}$. Todas estas notas son, en un primer momento, de tono muy gayesco. Si leemos la dedicada a Venecia nos da incluso la impresión de que contempla la Serenísima con los ojos de su mentor y amigo. El chapoteo del agua en los escalones de los canales, el irisado de las caracolas, los puentes chinescos, todo hace pensar en las maravillosas observaciones de Gaya de hacía unos años y

\footnotetext{
31 Op.cit., p.168. Señalemos de paso que, por el contrario, María Zambrano es machadiana, estando en su obra totalmente ausente la obra de Juan Ramón Jiménez.

32 R.Gaya, Obra completa, op.cit., p. 273.

33 T.Segovia, El tiempo en los brazos, op.cit., p. 288-289 y 292.

34 Op.cit., p. 295.

35 Cartas a Rosa Chacel, ed., introd. y notas de A.Rodríguez-Fischer, Cátedra, 1992.

36 Fueron posteriormente publicadas en Contra-corrientes, Universidad Nacional Autónoma de México, 1973, pp. 17-61, con el título de «Viaje a contrapelo».

37 Obra completa, op.cit., pp.331-354.
} 
que vuelven a aparecer en el 56, yo diría que incluso con mayor embeleso ${ }^{38}$. Las observaciones acerca de Roma son más parcas en el pintor. Su insistencia en el lado materno, redondeado, terreno, de la ciudad eterna vuelven a aparecer en Segovia pero esta vez con mayor desenvoltura e incluso capacidad evocadora. Fijémonos en que se sirve de un símbolo, la loba, para resaltar esa fertilidad y salvajismo de la ciudad, cosa que nunca había hecho su amigo pintor. Pero lo más destacable de su estampa es que insiste en la sensación de plenitud del presente, no de eternidad, en esa "ceremonia conmovedora del presente", en que todo es vivo, real, fraternal. Allá donde la Historia se hacía aparentemente más presente en su acumulación muchas veces heteróclita, en realidad, ella no "nublaba la imagen concreta de cada uno" de los hombres que la habían vivido. Y termina diciendo a propósito de Roma: "Obligada a vivir, no era sino la ocasión de este encuentro"39. La palabra «encuentro» es así la última de este ensayo.

Destacaría de las evocaciones de los tres autores la caracterización de la ciudad de Roma como una mujer. "Sus dos sílabas -dice el pintor-parecen los senos duros de una mujer feroz, antigua capitana, tierna, maternal". Y añade que es más "hembra" que femenina ${ }^{40}$. Para el poeta es "una loba tierna", "esa fiera maternal, feroz y protectora, armada de sus dientes y de su dulzura". Y, cuando mucho más tarde, evoque la filósofa la ciudad en la que vivió, dirá de ella que es "hija de una Venus nutricia" pues "Roma viene directamente de Afrodita, es decir de Venus, a través de Eneas y a través de Julio César" 41.

En torno al 15 de abril del 56, Segovia y Gaya llegan pues a Roma y se encuentran con María Zambrano. Según Tomás, los tres dieron varios paseos por la ciudad, en esos momentos en plena eclosión primaveral. Lo más seguro es que Tomás se dejase conducir por los dos insignes cicerones que le acompañaban. María pudo llevarlos por la Via Appia, por la zona del arco de Jano, donde se encuentra la iglesia de San Juan Degollado, por el Larario, en el monte Palatino ${ }^{22}$. Ramón pudo conducirlos hacia el Circo Máximo, Campidoglio, el Foro ("de una hermosura...doliente", apunta un atardecer con lluvia, en enero del 57) u otros lugares en donde amaba pintar, sobre todo a las orillas del Tíber, por el Lungotevere, cerca de la isla

38 Véanse, por ejemplo, op.cit., las observaciones de 1952, pp. 400-404, de 1953, pp. 429-444, y la del 56, pp. 451-452.

39 En T.Segovia, Contra-corrientes, p.52.

40 En una postal enviada por R.Gaya, desde París, el 3 de diciembre del 56, concluye sus breves palabras diciendo: "saluda a Esa Mujer y tú recibe un abrazo provisional de tu hermano en el agua y la ignorancia".

41 Véase, respectivamente, Obra Completa, op.cit., p.335; Contra-corrientes, op.cit., p.45; y «Roma, ciudad abierta y secreta», 1985, recogido en Las palabras del regreso, Amarú, Salamanca, 1995, pp.87-88.

42 Ver M.Zambrano, Las palabras del regreso, op.cit., pp.87-102. Véase también el libro de Laura Mariateresa Durante, La letteratura come esperienza filosofica nel pensiero di María Zambrano. Il periodo romano (1953-1964), Aracne, 2008. 
Tiberina43. Quién sabe si subieron por las escalinatas de Trinità dei Monti, cuyas hierbas entre los escalones le producen un día "una especie de agradecimiento" 44 . Al parecer recuerda Tomás haber estado una vez en la casa de María, en la Piazza del Popolo45.

Una frase que recuerda él haber escuchado bastantes veces a Ramón, asociada en su memoria a este viaje, dice lo siguiente: "cuando quieres enseñar algo a un amigo, siempre ha desaparecido". Según Isabel Verdejo, esta frase hay que relacionarla con la costumbre que tenían de subir, Ramón y ella, a lo alto del Campidoglio con los amigos que solían recibir de visita e intentar mostrarles un momento "indescriptible" del atardecer en que el "sol medianamente bajo acariciaba las ruinas", como muy bien expresa ella. Si se llegaba más tarde de ese momento, la "magia había desaparecido". César Antonio Molina recuerda haber ido con María a Santa María Aracoeli, no sabemos en qué época, y haber subido esas empinadas escalinatas que suben muy cerca de donde se encuentra el Campidoglio con la estatura de Marco Aurelio. Estamos en la colina capitolina, pero desde ahí no se puede ver el Foro. Hay que situarse en el mirador que hay del otro lado. Lo que me parece muy curioso es que habla también de un atardecer del mes de abril y, sobre todo, que María no prestase atención a los símbolos conmemorativos de la batalla de Lepanto situados en el interior del templo, que a él le habían llamado la atención, sino al "correr del disco solar en su caída por entre las puertas abiertas, de par en par, de la iglesia" 46.

La ligera disparidad en los dos recuerdos muestra tal vez una sensibilidad algo diferente en Zambrano y en Gaya. Mientras que en la primera parece estar presente el simbolismo del sol poniente entrando por la nave central de la iglesia, en el segundo aparece con más claridad lo fugitivo en el atardecer y la siempre difícil coincidencia simultanea de un mismo sentimiento poético en dos amigos. Esta tonalidad distinta se refuerza si pensamos en la frecuencia con que pintaba atardeceres Gaya y en las veces en que, en sus ensayos, reitera esa magia que tiene el atardecer de disipar todo lo adventicio, metamorfoseándolo todo, la luz, la tierra y el aire, en un pensamiento de lo real ${ }^{47}$. En contraste, Zambrano pensaba probablemente en que en ese lugar la sibila tiburtina profetizó a Augusto la venida de Jesucristo. Tal vez pensaba en la «Cruz de luz» de los mesalianos, heterodoxos del cristianismo, en la

43 Obra Completa, op.cit., p.461. Algunos de estos lugares son mencionados de nuevo el 26 de mayo de 1957 en un "paseo, por la tarde, maravilloso". Son, dice él, "los mismos lugares de siempre", p.467. 44 Obra Completa, p.464. Anotación del 25 de febrero de 1957.

45 Tenemos de Gaya un pastel de esta plaza, titulado «Il Popolo», fechado precisamente en 1956. En Ramón Gaya. La hora de la pintura, Fundació Caixa Catalunya, Barcelona, 2006, p.149.

46 Véase C. Antonio Molina, «María Zambrano, paseos por Roma», en http://cvc.cervantes.es/literatura/zambrano_roma/molina.htm

47 Cita en 1962 a Tiziano quien decía que el atardecer "es la hora de la Pintura" y añade que en dicho momento parece entregársenos "una realidad, diríamos, filtrada". En Obra Completa, op.cit., p.248. 
posibilidad de una religión no sacrificial, en el que Cristo se transubstanciase en luz divina, cercana a los neplatónicos 48 .

Vemos a los tres creadores recorrer las calles de Roma, intercambiando impresiones y proyectos, vidas segadas por el destierro de manera distinta en cada uno, pero, al mismo tiempo, engrandecidas por un nomadismo obligado, vuelto destino, "el corazón en medio del exilio", como dice Tomás en uno de los poemas escritos este año49. Viven un momento especial, nunca repetible. Un día en Italia, dice Ramón, es siempre "un día más" 50.

Aquí está, con nosotros, apretándonos fuerte como un lago, el ahora, el momento presente

Y termina su poema:

Aquí está; nada somos en sus manos de hierro. Mientras dure el presente Todo es vida, no es nuestro ${ }^{51}$.

María Zambrano también le estaba dando vueltas al misterio del tiempo, del presente, de la atemporalidad. En ese "Vivir el instante" había "ese anhelo de librarse de la sucesión, de despojarse del pasado y quedarse inocente". En «La multiplicidad de los tiempos»), antes mencionado, se pregunta por qué "la felicidad haya de tomar forzosamente la forma del instante, que es la unidad de los tiempos múltiples, la transparencia en el tiempo confuso". Fijémonos cómo esta palabra, «transparencia», tan importante en Gaya y en Zambrano, de indudable alcance metafísico en ambos, adquiere resonancias ligeramente diferentes, transparencia del diamante, de la luz, como reunión del yo fragmentado en su comparecencia ante los demás, adsum, y transparencia del mundo acuoso de lo real cuya emanación propia es la pintura. El esplendor romano se adueñaba de ellos y reflejaba en cada uno sentires distintos con respecto al pasado, la felicidad y el amor, el cual, dice ella, está "fuera de la historia", algo que tal vez iría en contra de la pretensión de Pittaluga de historiar las mujeres o incluso de historiar el amor, como ella misma lo había pretendido desde finales de los 40 .

\footnotetext{
48 Ver Cartas de La Pièce, op.cit., pp.270 y 317-320.

49 En T.Segovia, Poesía (1943-1997), FCE, México, 1998, p.172.

50 En Obra Completa, op.cit., p.479.

51 Algunos poemas de Ramón Gaya, Pre-Textos, 2001, p.39.
} 
También Segovia se preguntaba por aquel entonces si precisamente el arte de escribir un poema consistía en reunir un ramillete de tiempos distintos en un solo instante. El cumplimiento del día, el sentir el atardecer como logro apretado del día es algo que está en sus poemas de aquel tiempo.

Ya cerca de morir desborda el día,

lleno al fin de sí mismo52.

Ese tiempo, tal tiempo, "no volverá", pero sabe que el poeta puede dar testimonio de él pues ese día en que tuviste "el tiempo entre tus brazos", ese nombre del pasado sólo querrá decir algo "para los labios que lo dicen"53. Y el mismo mes de abril, en Roma, Tomás Segovia incide en ese "presente espeso" de esa ciudad "maternal". La impureza de esa ciudad, su suciedad de historia, como muy bien expresa en un verso, no le impide, al contrario, cantar el:

"Perpetuo instante del amor,

dulzura sin pasado, loba ciega:

otra vez eres limpia como el fuego" 54 .

Tomás me recordaba hace poco que en un paseo por el Lungotevere, María les habló "del mirto como planta de la muerte". Isabel Verdejo me comentaba que nunca le oyó a Gaya hablar de esto, pero añadía que en la subida a la colina del Aventino, partiendo del circo Máximo, hay una Via del valle Murcia. Es curioso pensar que uno de los orígenes etimológicos probables de la ciudad natal de Gaya sea el de campo de mirtos.

Gil de Biedma, de regreso de su viaje en Filipinas, allá por 1956 precisamente, y después de haber visitado a María a la ida, anota que fue solo, al parecer, a las dos de la noche, al templo de Venus «maravillosamente plantado de mirtos"55. ¿Se dirigió a ese lugar por indicación de María, después de haber ido con ella a la ida? No lo sabemos, pero es muy significativo que en la misma página, después de señalar esta visita, anote una cena con ella, en una trattoria, cerca de su casa. Por su parte, Tomás me dijo lo siguiente: "anduvimos por el Lungotévere después de haber visitado la Bocca de la Verità y el templo de Artemisa; creo que era algo relacionado con los mirtos". Me inclino a pensar que ese "templo de Artemisa" de su recuerdo, bien pudo ser el templo de Venus de la cita de Gil de Biedma. Y que quizá María les quiso mostrar, como a otros amigos, los mirtos que crecían junto a las ruinas del templo...

52 Poesia, op.cit., p. 151.

53 Op.cit., p. 165.

$54 \mathrm{El}$ poema «Roma», al cual pertenecen estos versos, es el único fechado en abril del 56, y en esta ciudad, de su poemario El sol y su eco. Ver Poesía, op.cit., p.150.

55 Jaime Gil de Biedma, Retrato del artista en 1956, RBA, 1993, p.122. 
El templo podría ser, más precisamente, el de Venus y de Roma, recientemente restaurado precisamente. No he encontrado referencias al mirto en la obra de Zambrano, pero es sabido que los mirtos se asocian a Venus y a la inmortalidad. ¿Del amor? ¿De la poesía? Cuenta Virgilio en la Eneida cómo Eneas descendió al infierno, por el Averno, guiado por la sibila de Cumas. Allá se encontró, entre otros, con Dido, su antigua amante en Cartago, quien se había suicidado antes por la huida de Eneas, cumpliendo éste el mandato de Venus, su madre, y de los dioses, en general, de fundar la ciudad de Roma ${ }^{56}$. El bosque oscuro en donde encuentra a Dido, errante, es un bosque de mirtos....Dice Virgilio que cuando Eneas se dio cuenta de que era efectivamente ella -a modo de "sombra pálida", como dice Virgilio- se puso a llorar... ${ }^{57}$ Esos mirtos que seguían creciendo a la vera del templo eran, pues, fantasmas sacados únicamente de la pluma de un poeta antiguo o de narraciones mitológicas, sino que crecían realmente al lado del templo de Venus, como ofrenda espontánea de la naturaleza a su diosa protectora, como tributo discreto, pero hermoso, de la dicha del instante y del dolor del pasado.

Veo a los tres, enfrente de las columnas del templo, a Ramón rumiando con sus ojos la luz de las hojas del arbusto, a Tomás alegre, tal vez, o conmovido, por contemplar la encarnación siempre concreta de los mitos, y a María, pensando quizá en Gustavo Pittaluga, cuyo amor no fue correspondido, al parecer, por ella, o quién sabe, pensando en la sabia eterna del amor, transubstanciada en luz y en vida58.

Creo, en fin, que el sentido profundo de este encuentro fue el de hacernos descubrir un nuevo sentido poético de lo real. Los tres lo exploraron desde ángulos distintos, los tres permanecerán fieles a esta llamada de lo real. Los tres nos enseñan, en estos aciagos inicios del siglo XXI, que lo real sólo puede ser escuchado en un esfuerzo generoso, misericordioso, pasivo y heroico, hacia lo otro, por debajo de las ideologías, del consumismo y de las pululantes pantallas de todo tipo que nos lo velan, erigiendo realidades mostrencas y lenitivas.

Sí, Ramón Gaya fue un puente entre Zambrano y Segovia, como esos puentes delicados que pintaba Ramón en Florencia, en Venecia, en Roma, en París, delicados pero recios, sólidos como un abrazo fraterno 59 . Ya dijo Nietzsche que la "grandeza del hombre está en ser un puente y no una meta: lo que en el hombre se puede

\footnotetext{
56 Virgilio, Eneida, libro VI, verso 440 en adelante.

57 Me remito a la versión bilingüe, francés/latín, de la Énéide, traducción de André Bellessort, Les Belles Lettres, París, 1964, vol. I, p.180.

58 En Carta de G.Pittaluga a María, del 4 de agosto, probablemente del 53, le escribe estas palabras: "solo me queda suplicarte que me conserves un poco de aquel sentimiento que no sé ya cómo llamar de honda ligazón que me une a tí. Te quiero mucho. Y tú lo sabes, lo sabes más de lo que quieres reconocerlo".

59 Incluso una postal que le envía Ramón desde París a María el 31 de agosto del 56 muestra una foto del Puente de las Artes, con el Instituto de Francia y el Palacio de la Moneda, al fondo.
} 
amar es que es un tránsito y un ocaso"60. Ramón Gaya no influyó en ellos, en sentido estricto, fluyó entre ellos, como los ríos esplendorosos que pintó, y, por fortuna, mucho más tarde, fluyó entre nosotros.

Ricardo Tejada Mínguez

Université du Maine

Grupo de investigación Marges

Université Lyon III

60 F.Nietzsche, Así habló Zaratustra, Alianza Editorial, 1985, p.36. 